\title{
Antibacterial and Antioxidant Capacity of Polar Microorganisms Isolated from Arctic Lichen Ochrolechia sp.
}

\author{
MI-KYEONG KIM ${ }^{1}$, HYUN PARK ${ }^{2}$ and TAE-JIN OH ${ }^{1 *}$ \\ ${ }^{1}$ Department of Pharmaceutical Engineering, SunMoon University \\ Chungnam 336-708, South Korea \\ ${ }^{2}$ Korea Polar Research Institute (KOPRI), Incheon 406-840, South Korea \\ Submitted 21 November 2013, Revised 14 July 2014, Accepted 17 July 2014
}

\begin{abstract}
Although many scientists have been studying lichens, the bacterial communities among lichens have not been fully explored. In this study, the biological activities of bacterial isolates from Arctic lichen Ochrolechia sp. were screened. Cell cultures were extracted using ethyl acetate, and these cultures were tested for antibacterial and antioxidant activities. To evaluate the antibacterial activities, we carried out a disk diffusion test and minimum inhibitory concentration assay. The inhibition zone diameter $(\mathrm{mm})$ was 8 to 12 , and its MIC value ranged from 222.0 to $>1000 \mu \mathrm{g} / \mathrm{ml}$ (control antibiotic ampicillin ranged from 0.31 to $0.58 \mu \mathrm{g} / \mathrm{ml}$ ). PAMC26625 (Sphingomonas sp., sequence similarity: $99.108 \%$ ) showed a high amount of total phenolic and total flavonoid contents within 5 extracts and also exhibited $77.23 \%$ and $80.02 \%$ in the 1,1-diphenyl-2-picryl-hydrazyl assay and the 2,2'-azino-bis(3-ethyl benzothiazoline-6-sulphonic acid) assay, respectively. In the ferric reducing antioxidant power assay, it was determined that PAMC26625 contained a higher amount of ferrous ion [ $8.72 \mathrm{mM}$ $\mathrm{Fe}(\mathrm{II}) / \mathrm{mg}$ extract] than control ascorbic acid $[6.21 \mathrm{mM} \mathrm{Fe}(\mathrm{II}) / \mathrm{mg}$ extract $]$. Our data indicated that they had potential to be novel sources of antibacterials and antioxidants.
\end{abstract}

Key words: Arctic, antibacterial/antioxidant activity, bacterial association, lichen, Ochrolechia sp.

\section{Introduction}

Lichens are symbiotic organisms that are composed of a fungus and an alga, and they can survive in extreme environments such as tropical, desert, and polar regions. Lichens and their natural products have been used as cosmetics, decorations, dyes, foods, and medicines (Oksanen, 2006). They have been attracting the attention of many researchers because of their diverse pharmaceutical potentials as shown in their antiviral, anti-proliferative, anti-inflammatory, anti-tumor, and antimycobacterial activities (Ingólfsdóttir et al., 1998; Lauterwein et al., 1995; Lawrey, 1989; Molnár and Farkas, 2010; Morita et al., 2009). Also, lichens are considered to be a source of natural antioxidants because while synthetic antioxidants such as butylated hydroxyanisole (BHA), butylated hydroxytoluene (BHT), and tertiary butylhydroquinone (TBHQ) are commercially available, they have proven to be highly carcinogenic (Grice, 1996). Because of the lichens' inhibitory effects against microorganisms, their antimicrobial activities have also been widely investigated. In general, the natu- ral products from lichens are their secondary metabolites, called "lichen substance", and most of these come from the fungal symbionts in lichens (Luo et al., 2011; Stocker-Wörgötter, 2008).

Recent molecular studies have suggested a variety of bacterial communities among lichens, including their structural and ecological contributions. For examples, Gonzales et al. (2005) described the diversity of actinomycetes among lichens by DNA fingerprinting; they also evaluated the genes involved in the secondary metabolite production of 337 isolates. Cardinale et al. (2006 and 2008) showed that diverse bacteria are present in lichens by the analysis of their ribosomal internal transcribed spacer polymorphism and by fluorescence in situ hybridization analysis. Grube et al. (2009) also analyzed and compared the structure and composition of associated bacterial communities of some lichen species using combined microscopic and molecular techniques; however, their biological activities have not been studied in detail. The biological activities and bacterial diversity of Arctic lichen Ochrolechia sp. are still unknown. In previous studies, we screened

\footnotetext{
* Corresponding author: Tae-Jin Oh, Department of Pharmaceutical Engineering, SunMoon University, \#100, Kalsan-ri, Tangjeong-myeon, Asan, Chungnam 336-708, South Korea; phone: +82(41)530-2677; fax: +82(41)530-2279; e-mail: tjoh3782@sunmoon.ac.kr
} 
nine bacterial isolates from Arctic lichen Cladonia sp., Sterocaulon sp., Stereocaulon sp., and Umbilicaria sp. and evaluated their antibacterial and antioxidant activities. We found that bacterial isolates from lichen exhibited some antibacterial activities against Gram-positive and Gram-negative clinically isolated microorganisms. They also showed better antioxidant activity than the control ascorbic acid (vitamin C). Therefore, the aim of this study was to screen the microorganisms from lichen Ochrolechia sp., and evaluate their antibacterial potential against six test microorganisms and discern their antioxidant potential.

\section{Experimental}

\section{Materials and Methods}

Collection and identification of lichen samples. Lichen Ochrolechia sp. was collected in Ny-Ålesund, Svalbard, Dasan Korean Arctic Station (78, 91.140' N/ 011, 94.878 ' E) by the Korean Polar Research Institute (KOPRI). It was transferred at room temperature and stored at $-20^{\circ} \mathrm{C}$ until further use. Bacterial isolates were deposited in polar and alpine microbial collection (PAMC).

Screening of microorganisms associates with lichen. The isolation of microorganisms was performed by KOPRI. Fragments from lichen thalluses were separated by sterilized scissors or knife. Sterilized $0.85 \%$ $\mathrm{NaCl}$ solution was added and this was followed by vortexing for $10 \mathrm{~min}$. The solution was then discarded, and the steps above were repeated three times. The tissue was subsequently broken with a mortar in sterilized $0.85 \% \mathrm{NaCl}$ solution. After spreading the tissue on malt extract-yeast extract (MY) agar media and Reasoner's $2 \mathrm{~A}(\mathrm{R} 2 \mathrm{~A})$ agar, it was incubated at $10^{\circ} \mathrm{C}$ for 15 to 21 days. To obtain pure single colonies, subculturing was repeated three times and it was preserved at $-80^{\circ} \mathrm{C}$ in $20 \%$ glycerol. The obtained bacterial isolates were identified by $16 \mathrm{~S}$ rRNA gene sequences analysis. The 16S rRNA gene was amplified from a single colony of pure culture with two universal primers: $27 \mathrm{~F}$ (5'AGA GTT TGA TCM TGG CTC AG-3') and 1492R (5'-GGT TAC CTT GTT ACG ACT T-3') as described by Lane (1991). Polymerase chain reaction (PCR) was carried out with $25 \mu \mathrm{l}$ reaction mixtures containing 1X PCR reaction buffer, $200 \mu \mathrm{M}$ of dNTPs, $0.2 \mu \mathrm{M}$ of each primer, a single colony as a template, and 1 unit of Taq DNA polymerase (In-Sung Science, Suwon, South Korea). The PCR procedure included an initial denaturing step at $95^{\circ} \mathrm{C}$ for $5 \mathrm{~min}$ and 30 cycles of amplification $\left(95^{\circ} \mathrm{C}\right.$ for $30 \mathrm{~s}, 56^{\circ} \mathrm{C}$ for $30 \mathrm{~s}$, and $72^{\circ} \mathrm{C}$ for $30 \mathrm{~s}$ ) and a final extension step at $72^{\circ} \mathrm{C}$ for $5 \mathrm{~min}$. PCR products were purified with an AccuPrep PCR Purification Kit
(Bioneer, Daejeon, South Korea) and sequenced with the same primer used for PCR amplification. The sequence of the $16 \mathrm{~S}$ rRNA gene was compared with that of type strains available in the database to find closely related species. All sample numbers were given by PAMC in KOPRI.

Culture and extraction of bacterial isolates. A total of five bacterial isolates were cultured in $50 \mathrm{ml}$ of MY ( $4.0 \mathrm{~g}$ malt extract, $4.0 \mathrm{~g}$ yeast extract, $10.0 \mathrm{~g}$ glucose, and $1.0 \mathrm{~L}, \mathrm{pH} 7.2$ distilled water) and $\mathrm{R} 2 \mathrm{~A}(0.5 \mathrm{~g}$ proteose peptone, $0.5 \mathrm{~g}$ casamino acids, $0.5 \mathrm{~g}$ yeast extract, $0.5 \mathrm{~g}$ dextrose, $0.5 \mathrm{~g}$ soluble starch, $0.3 \mathrm{~g}$ dipotassium phosphate, $0.05 \mathrm{~g}$ magnesium sulfate $7 \mathrm{H}_{2} \mathrm{O}, 0.3 \mathrm{~g}$ sodium pyruvate, and $1.0 \mathrm{~L}, \mathrm{pH} 7.2$ distilled water) liquid media at $15^{\circ} \mathrm{C}$ for 10 to 15 days. The culture broth was added to a double volume of ethyl acetate which was of analytical grade (Daejung, Shiheung, South Korea). Extraction was performed individually on each solvent at room temperature and then the layer of culture media was discarded after 2 hours. The solvent layer was concentrated using a rotary evaporator, and the obtained dried crude extract was dissolved in $500 \mu \mathrm{l}$ of ethyl acetate. The concentrations of extract ranged from $1.2 \mathrm{~g} / \mathrm{ml}$ to $1 / 7 \mathrm{~g} / \mathrm{ml}$. Each extract was diluted to $1 \mathrm{mg} / \mathrm{ml}$ for further experiments.

Evaluation of the antimicrobial activities of test microorganisms. Ethyl acetate extracts were tested against the 3 Gram-positive bacteria Staphylococcus aureus (KCTC1927), Bacillus subtilis (KCTC1028), and Micrococcus luteus (KCTC9341), and 3 Gram-negative bacteria Escherichia coli (KCTC1682), Pseudomonas aeruginosa (KCTC1637), and Enterobacter cloacae (KCTC1685) used in this study. All of the six test strains are known as clinical isolates. They were purchased from the Korean Collection for Type Cultures (KCTC) and Korea Research Institute of Bioscience and Biotechnology (KRIBB, Daejeon, South Korea). All bacterial isolates were kept on Luria-Bertani (LB; $10.0 \mathrm{~g}$ trypton, $5.0 \mathrm{~g}$ yeast extract, $10.0 \mathrm{~g} \mathrm{NaCl}$, and $1.0 \mathrm{~L}, \mathrm{pH} 7.2$ distilled water) at $4^{\circ} \mathrm{C}$.

Paper disk diffusion test. The paper disk diffusion test was performed according to Bauer et al. (1966) with some modifications. All reagents were purchases from Difco (Franklin Lakes, USA). Bacterial cells were standardized to $0.5 \mathrm{McF}$ arland and then mixed with soft agar $(0.04 \mathrm{~g} / \mathrm{ml}) .9 \mathrm{ml}$ of this mixture was inoculated onto Mueller-Hinton agar plates. Afterwards, each extract was loaded into paper disks ( $6 \mathrm{~mm}$ in diameter, Advantec, Osaka, Japan) and transferred onto the plates inoculated with the bacterial strains. Disks loaded with ethyl acetate were used as a control. All inoculated culture plates were incubated at $37^{\circ} \mathrm{C}$, and the inhibition zones of bacterial growth were measured after 12 to $18 \mathrm{~h}$.

Minimum inhibitory concentration (MIC) test. MIC was determined by the broth dilution method 
(Swenson et al., 1982) with some modifications. Dilutions of culture extract ranged from 0 to $1000 \mu \mathrm{g} / \mathrm{ml}$ in $5 \mathrm{ml}$ of Mueller-Hinton broth. Final concentrations of test organisms were adjusted to $10^{6} \mathrm{CFU} / \mathrm{ml}$. The inoculated tubes were incubated in a shaker $(250 \mathrm{rpm})$ at $37^{\circ} \mathrm{C}$ for $24 \mathrm{~h}$. MIC was measured by a UV-Vis spectrophotometer at $600 \mathrm{~nm}$ to determine growth.

Evaluation of antioxidant activities: total phenolic contents (TPC) and total flavonoid contents (TFC) tests. TPC was evaluated by the Folin-Ciocalteu reagent according to the method of Slinkard and Singleton (1977) with some modifications. All of the chemical reagents were purchased from Sigma-Aldrich (St. Louis, USA). The reaction mixture was incubated for $30 \mathrm{~min}$ at room temperature and the absorbance was determined at $760 \mathrm{~nm}$ using a UV/Vis spectrophotometer (Biochrom, Holliston, USA). Gallic acid used as the positive control and the reaction mixture without the extract was used as the negative control. The concentration of TPC was expressed in milligrams of gallic acid equivalent (GAE) per g of extract. TFC was evaluated by the colorimetric method described previously (Zhishen and Mengcheng, 1999). The absorbance of reaction mixture was measured at $510 \mathrm{~nm}$ using a UV/ vis spectrophotometer. Catechin was used as a standard compound for the quantification of total flavonoids. All the values were expressed as milligrams of catechin equivalent (CE) per gram of extract. Each extract was measured three times.

Free radical scavenging activity using $\mathrm{DPPH}$ and ABTS. The free radical scavenging activity of the extract was measured by 1,1-diphenyl-2-picrylhydrazyl (DPPH) and 2,2'-azino-bis[3-ethyl benzothiazoline-6-sulphonic acid] (ABTS) reagents and they were purchased from Sigma-Aldrich (St. Louis, USA). The DPPH free-radical scavenging activity of the five extracts was determined by the method of Blois (1958) with some modifications. The reaction mixture was incubated for $30 \mathrm{~min}$ at room temperature, and the absorbance was measured at $517 \mathrm{~nm}$ using a UV-visible spectrophotometer. $1 \mathrm{mM}$ of ascorbic acid (vitamin C) was used as a positive control and pure ethyl acetate without extract was used as a negative control. The ABTS assay is also frequently used to measure antioxidant activities. The procedure that was used followed the method of Arnao (2010) with some modifications. The absorbance of reaction mixture was measured at $734 \mathrm{~nm}$ using a UV visible spectrophotometer. $1 \mathrm{mM}$ of ascorbic acid was used as a positive control and pure solvents without the test sample were taken as a negative control. Free radical scavenging activity was described as the inhibitory percentage of $\mathrm{DPPH}$ and ABTS was calculated according to the following equation, with each extract measured three times: scavenging activity $(\%)=[1-($ Abs sample/Abs control $)] \times 100$.
Ferric reducing antioxidant power (FRAP) assay. The FRAP assay was carried out according to the modified Benzie and Strain method (1996) while all of chemical reagents were purchased from Sigma-Aldrich (St. Louis, USA). The absorbance of reaction mixture was measured at $593 \mathrm{~nm}$ using a UV/Vis spectrophotometer. Temperature was maintained at $37^{\circ} \mathrm{C}$. The readings at $30 \mathrm{~min}$ were selected for the calculation of FRAP values.

Statistical analysis. All analyses were carried out in triplicates. The experimental values are the mean \pm standard deviation (SD). Statistical comparisons using one-way analysis of variance (ANOVA) with $\mathrm{p}<0.05$ were regarded as significant, with $\mathrm{p}<0.01$ being highly significant.

\section{Results and Discussion}

Evaluation of antibacterial properties. A total of five bacteria were isolated from the Arctic lichen Ochrolechia sp (Table I). To evaluate the antibacterial potential of extracts from our bacterial isolates, a paper disk diffusion test and an MIC test were carried out. In the paper disk diffusion test, all of the five bacterial isolates showed antibacterial activities against both Grampositive (S. aureus, B. subtilis, and M. luteus) and Gramnegative (E. cloacae, P. aeruginosa, and E. coli) bacteria. No antibacterial activity was observed in the control (disk without extract, only ethyl acetate), while the antibacterial strengths of our extract were similar with the zone of inhibition diameter ranging from 8 to $12 \mathrm{~mm}$ (Table II). Also, while the MIC test was carried out, we used ampicillin as control antibiotics because all of the Gram-positive and Gram-negative tested organisms had sensitive resistance to ampicillin. The MIC for the extracts in the tested bacteria was 222.0 to $>1000 \mu \mathrm{g} /$ $\mathrm{ml}$ and all of the extracts inhibited the tested organism at higher concentrations compared to control ampicillin (from 0.31 to $0.58 \mu \mathrm{g} / \mathrm{ml}$ ) (Table III). According to the $16 \mathrm{~S}$ rRNA gene sequencing results, their sequence

Table I

Microorganisms isolated from the Arctic lichen Ochrolechia sp.

\begin{tabular}{|c|c|l|c|}
\hline $\begin{array}{c}\text { PAMC } \\
\text { No. }\end{array}$ & $\begin{array}{c}\text { Isolation } \\
\text { media }\end{array}$ & $\begin{array}{c}\text { Bacterial species } \\
\text { (Closest strain) }\end{array}$ & $\begin{array}{c}\text { Similarity } \\
(\%)\end{array}$ \\
\hline 26605 & MY & Sphingomonas sp. & 98.888 \\
\hline 26606 & R2A & Burkholderia sp. & 98.401 \\
\hline 26607 & R2A & Burkholderia sp. & 99.296 \\
\hline 26608 & R2A & Burkholderia sp. & 99.763 \\
\hline 26625 & MY & Sphingomonas sp. & 99.763 \\
\hline
\end{tabular}

* The value are expressed as sequence similarity with the closely related organisms and generated by Basic Local Alignment Search Tool (BLAST) search program (http://blast.ncbi.nlm.gov/Blast). 
Table II

Inhibition zone diameter of microorganisms isolated from the Arctic lichen Ochrolechia sp.

\begin{tabular}{|c|c|c|c|c|c|c|}
\hline \multirow{2}{*}{$\begin{array}{c}\text { Sample } \\
\text { No. }\end{array}$} & \multicolumn{3}{|c|}{ Gram-positive } & \multicolumn{3}{c|}{ Gram-negative } \\
\cline { 2 - 7 } & S. aureus & B. subtilis & M. luteus & E. cloacae & P. aeruginosa & E. coli \\
\hline 26605 & ++ & + & - & - & + & ++ \\
\hline 26606 & - & + & ++ & - & ++ & - \\
\hline 26607 & ++ & - & - & - & - & ++ \\
\hline 26608 & + & +++ & - & - & + & ++ \\
\hline 26625 & ++ & - & - & - & ++ & +++ \\
\hline
\end{tabular}

Each value was expressed in mm against test clinical isolates (-, no activity; +, $8 \mathrm{~mm} ;++, 9 \sim 11 \mathrm{~mm}$; +++, $12 \mathrm{~mm}$ ).

Table III

MIC of microorganisms isolated from Arctic lichen Ochrolechia sp.

\begin{tabular}{|l|c|c|c|c|c|c|}
\hline \multirow{2}{*}{$\begin{array}{c}\text { Sample } \\
\text { No. }\end{array}$} & \multicolumn{3}{|c|}{ Gram-positive } & \multicolumn{3}{c|}{ Gram-negative } \\
\cline { 2 - 7 } & S. aureus & B. subtilis & M. luteus & E. cloacae & P. aeruginosa & E. coli \\
\hline 26605 & $>1000$ & $571.4 \pm 0.19$ & $>1000$ & $>1000$ & $>1000$ & $518.3 \pm 0.13$ \\
\hline 26606 & $303.1 \pm 0.35$ & $>1000$ & $>1000$ & $>1000$ & $523.7 \pm 0.21$ & $>1000$ \\
\hline 26607 & $324.7 \pm 0.24$ & $602.1 \pm 0.26$ & $>1000$ & $>1000$ & $491.5 \pm 0.66$ & $531.7 \pm 0.32$ \\
\hline 26608 & $409.8 \pm 0.27$ & $428.6 \pm 0.23$ & $>1000$ & $>1000$ & $408.9 \pm 0.13$ & $433.0 \pm 0.56$ \\
\hline 26625 & $233.1 \pm 0.16$ & $>1000$ & $>1000$ & $>1000$ & $222.0 \pm 0.95$ & $417.2 \pm 0.44$ \\
\hline Ampicillin & $0.58 \pm 0.09$ & $0.31 \pm 0.05$ & $0.49 \pm 0.07$ & $0.4 \pm 0.08$ & $0.48 \pm 0.09$ & $0.35 \pm 0.02$ \\
\hline
\end{tabular}

Each value is expressed as mean $\pm \mathrm{SD}(\mu \mathrm{g} / \mathrm{ml})$. Ampicillin used as a positive control.

similarities are almost the same and the species name of some of these are also the same. However, the morphological, chemical, and biological characteristics of the bacterial associates are somewhat different (data not shown). There are even differences in antibacterial activities among them. It is possible that media composition such as carbon source and/or nitrogen source may have affected the active compound of each extract. To search for new antibacterial sources from nature, a variety of lichen has been screened (Bhattarai et al., 2013; Celenza et al., 2013; Paudel et al., 2008 and 2010; Sultana and Afolayan, 2011). As for the lichen Ochrolechia species, however, there are few studies about their biological activities and active components (Millot et al., 2007; Ranković et al., 2010). Ranković et al. (2010) studied the antimicrobial activity of some lichens, including Ochrolechia androgyna, but not the bacterial associates of O. androgyna. Although antibacterial activities were lower than those of natural lichen O. adrogyna, the obtained results indicated that the bacterial isolates described in this study had the potential to be a source of treatment for various diseases caused by these clinical isolates or related microorganisms.

Evaluation of antioxidant properties. Many publications concerning the antioxidant activities of lichen have been reported (Behera et al., 2008; Gulluce et al., 2006; Kosanic et al., 2011; Luo et al., 2011; Stocker-Wörgötter, 2008). However, most of them used lichen or their fungal symbionts as their study resource. Although bacterial symbionts are also present in lichens and they contribute to lichens structurally and ecologically (Cardinale et al., 2006 and 2008; Gonzales et al., 2005; Grube et al., 2009), the biological activity of bacterial symbionts is still unexplored. Thus, the antioxidant potential of bacterial symbionts was evaluated. In general, antioxidant activity is dependent on phenolic contents and/or flavonoids contents (Halvorsen et al., 2002; Gardner et al., 2000; Pietta, 2000). Thus, TPC and TFC assays were carried out (Table IV). TPC values ranged from 1.07 (PAMC26607, B. sordidicola) to 10.44 (PAMC26625, Sphingomonas sp.) milligrams of GAE per gram of extract, and the TFC value ranged from 0.99 (PAMC26606, B. sordidicola) to 8.95 (PAMC26625, Sphingomonas sp.) milligrams of CE per gram of extract. PAMC26625 had the highest value of TPC and TFC among these extracts while Sphingomonas species had a higher amount of TPC and TFC than Burkholderia species in terms of bacterial species. Through these results, it was expected that PAMC26625 would have the strongest antioxidant activities. PAMC26625 showed $77.23 \%$ and $80.02 \%$ high, free-radical scavenging activity in the DPPH and ABTS assays (Table IV), respectively (control vitamin C was $29.31 \%$ ). Extracts that have high amounts of phenolic and/or flavonoid content showed high antioxidant activities as expected. In the case of PAMC26607 and PAMC26605, however, the free radical scavenging activity of PAMC26605 showed stronger activity 
Table IV

Evaluation of antioxidant activities of microorganisms isolated from the Arctic lichen Ochrolechia sp.

\begin{tabular}{|l|c|c|c|c|c|}
\hline \multirow{2}{*}{$\begin{array}{c}\text { Sample } \\
\text { No. }\end{array}$} & \multicolumn{5}{|c|}{ Evaluation of antioxidant activities } \\
\cline { 2 - 6 } & TPC $^{*}$ & TFC & DPPH $^{* * *}$ & ABTS $^{* * * *}$ & FRAP $^{* * * *}$ \\
\hline 26605 & $1.09 \pm 0.11$ & $5.46 \pm 0.05$ & $24.18 \pm 0.66$ & $22.73 \pm 0.87$ & $3.07 \pm 0.16$ \\
\hline 26606 & $1.32 \pm 0.18$ & $0.99 \pm 0.07$ & $5.31 \pm 0.17$ & $6.55 \pm 0.12$ & $1.14 \pm 0.11$ \\
\hline 26607 & $1.07 \pm 0.11$ & $1.65 \pm 0.10$ & $7.82 \pm 0.13$ & $5.91 \pm 0.09$ & $1.09 \pm 0.09$ \\
\hline 26608 & $2.02 \pm 0.08$ & $5.27 \pm 0.13$ & $26.66 \pm 0.15$ & $28.97 \pm 0.21$ & $4.16 \pm 0.08$ \\
\hline 26625 & $10.44 \pm 0.04$ & $8.95 \pm 0.05$ & $77.23 \pm 0.96$ & $80.02 \pm 0.92$ & $8.72 \pm 0.22$ \\
\hline
\end{tabular}

Each value is expressed as mean \pm SD.

* TPC (total phenolic contents) are expressed as gallic acid equivalents (mg GAE/g extract)

** TFC (total flavonoid contents) are expressed as catechin equivalents (mg CE g extract)

*** DPPH (1,1-diphenyl-2-picryl-hydrazyl) and ABTS [2,2'-amino-bis(3-ethyl benzothiazoline6-sulphoric acid)] ; free radical scavenging activity was described as the inhibitory percentage of DPPH and ABTS

${ }^{* * * *}$ FRAP (ferric reducing antioxidant power) are expressed as $\mathrm{mM} \mathrm{Fe}(\mathrm{II}) / \mathrm{mg}$ extract

than that of PAMC26607-about 3.1 fold and 3.8 fold in both the DPPH and ABTS assays-while they have comparable values of TPC. It may be that all phenolics do not have same antioxidant activity and some of them may possess strong activity whereas others have weak activity. It is possible that there are synergistic or antagonistic interactions between phenolic compounds or different types of components such as carbohydrates and proteins (Rice-Evans et al., 1995). The FRAP assay was also carried out due to its simplicity and reproducibility (Table IV). The reducing activity of the extract can evaluate based on the theory that antioxidants act as reductants by performing the reduction of ferric ions to ferrous ions (Benzie and Strain, 1996). Therefore, the determination of the ferrous ion formation can be used to predict the reducing power of the samples. The FRAP value of the extract varied from 1.09 to $8.72 \mathrm{mM}$ of ferrous ion per $\mathrm{mg}$ of extract, and the significantly higher $(\mathrm{p}<0.05)$ amount of ferrous ion was detected in PAMC26625. Other extracts had a lower amount of ferrous ions than the ascorbic acid that was used as a control $(6.81 \pm 0.44 \mathrm{mM} \mathrm{Fe}(\mathrm{II}) /$ mg extract). Finally, the results of this research suggest that the extract of PAMC26625 showed high antioxidant activity compared with control ascorbic acid. Moreover, our obtained results indicate that bacteria from lichen possess antioxidant activity and could be considered as potential sources of natural antioxidants.

Conclusions. In this paper, the antibacterial and antioxidant potentials of five bacterial symbionts from the lichen Ochrolechia sp. were evaluated, with PAMC26625 finally showing the strongest antioxidant activities among these five bacterial isolates. Although the functional compounds were not confirmed, they have the potential to be a novel source of antibacterials and antioxidants.

Paudel et al. (2008) found that the antioxidant activity of crude extract from polar lichen was more effective than other lichen species from tropical and temperate regions. It is expected that bacterial symbionts will follow a similar pattern. Thus, the biological activities of the bacterial symbionts in lichen that can be found in extreme environments from polar to desert can be compared.

It appears that this is the first study investigating the biological activity of bacterial associates isolated from the Arctic lichen Ochrolechia sp. Since most identified lichen substances come from the fungal symbionts of lichen, it is a novel approach to search for new antibacterial and antioxidant compounds from nature. In addition to this, this kind of study may help illuminate the unique survival mechanisms of lichen in extreme conditions. Therefore, it is important to screen and isolate microorganisms from lichens and investigate their biological activities in detail.

\section{Acknowledgments}

This study was supported by the Antarctic organisms: ColdAdaptation Mechanisms and its application grant (PE14070) funded by the Korea Polar Research Institute.

\section{Literature}

Arnao M.B., A. Cano and M. Acosta. 2010. The hycrophilic and lipophilic contribution to total antioxidant activity. Food Chem. 73: 239-244.

Bauer A.W., M.M. Kirby, J.C. Sherris and M. Truck. 1966. Antibiotic susceptibility testing by a standardized single disk method. Am. J. Clinic. Pathol. 45: 493-496.

Behera B.C., N. Verma, A. Sonone and U. Makhija. 2008. Antioxidant and antibacterial properties of some culture lichens. Bioresour. Technol. 99: 776-784. 
Benzie I.F.F. and J.J. Strain. 1996. The ferric reducing antioxidant ability of plasma (FRAP) as a measure of "antioxidant power": the FRAP assay. Anal. Biochem. 239: 70-76.

Bhattarai H.D., T. Kim, H. Oh and J.H. Yim. 2013. A new pseudodepsidone from the Antarctic lichen Stereocaulon alpinum and its antioxidant, antibacterial activity. J. Antibiot. (Tokyo) 66: 559-61.

Blois M.S. 1958. Antioxidant determinations by the use of a stable free radical. Nature 26: 1199-1200

Cardinale M., A.M. Puglia and M. Grube. 2006. Molecular analysis of lichen-associated bacterial communities. FEMS Microbiol. Ecol. 57: 484-495.

Cardinale M., J.Jr. Vieria de Castro, H. Müller, G. Berg and M. Grube. 2008. In situ analysis of he bacterial community associated with the reindeer lichen Cladonia arbuscula reveals predominance of Alphaproteobacteria. FEMS Microbiol. Ecol. 66: 63-71.

Celenza G., B. Segatore, D. Setacci, M. Perilli, F. Brisdelli, P. Bellio, M. Piovano, J.A. Garbarino, G. Amicosante and M. Nicoletti. 2012. Antibacterial activity of selected metabolites Chilean lichen species against methicillin-resistant staphylococci. Nat. Prod. Res. 27: $1528-1531$

Gardner P.T., T.A.C. White, D.B. McPhail and G.G. Duthie. 2000. The relative contributions of vitamin $\mathrm{C}$, carotenoids and phenolics to the antioxidant potential of fruit juices. Food Chem. 68: 471-474. González I., A. Ayuso-Sacido, A. Anderson and O. Genilloud. 2005. Actinomycetes isolated from lichens : evaluation of their diversity and detection of biosynthetic gene sequences. FEMS Microbiol. Ecol. 54: 401-415.

Grice H.C. 1996. Safety evaluation of butylatedhydroxytoluene (BHT) in the liver, lung and gastrointestinal tract. Food Chem. 54: 401-415. Grube M., M. Cardinale, J.Jr. Vieria de Castro, H. Müller and G. Berg. 2009. Species-specific structural and functional diversity of bacterial communities in lichen symbioses. ISME J. 3: 1105-1115. Gulluce M., A. Aslan, M. Sokmen, F. Sahin, A. Adiguzel, G. Agar and A. Sokmen. 2006. Screening the antioxidant and antimicrobial properties of the lichens Parmella saxatilis, Platismatia glauca, Ramalina pollinaria, Ramalina polymorpha and Umbilicaria nylanderiana. Phytomedicine 13: 515-521.

Halvorsen B.L., K. Holte, M.C.W. Myhrstad, I. Barikmo, E. Hvattum, S.F. Rember, A.B. Wold, K. Haffner, H. Baugerød, L.F. Andersen, Q. Moskaug, D.R.Jr. Jacobs and R. Blomhoff. 2002. A systematic screening of total antioxidants in dietary plants. J. Nutr. 132: 461-471.

Ingólfsdóttir K., G.A.C. Chung, V.G. Skúlason, S.R. Gissurarson and M. Vilhelmsdóttir. 1998. Antimycobacterial activity of lichens metabolites in vitro. Eur. J. Pharm. Sci. 6: 141-144.

Kosanić M., B. Ranković and J. Vukojević. 2011. Antioxidant properties of some lichen species. Int. J. Food Sci. Technol. 48: 584-598. Lane D.J. 1991. 16S/23S rRNA sequencing, In Nucleic acid techniques in bacterial systematic (Stackebrandt, E. \& Goodfellow, M., eds.): pp. 115-175. New York: John Wiley \& Sons Press.

Lauterwein M., M. Oethinger, K. Belsner, T. Peters and R. Marre. 1995. In vitro activities of the lichen secondary metabolites vulpinic acid, (+)-usnic acid, and (-)-usnic acid against aerobic and anaerobic microorganisms. Antimicrob. Agents Chemother. 39: 2541-2523. Lawrey J.D. 1989. Lichen secondary compound : evidence for a correspondence between antiherbivore and antimicrobial function. J. Bryol. 92: 326-328.

Luo H., Y. Yamamoto, H.S. Jeon, Y.P. Liu, J.S. Jung, Y.J. Koh and J.S. Hur. 2011. Production of anti-helicobacter pylori metabolites by the lichen-forming fungus Nephromopsis pallescens. J. Microbiol. 49: 66-70.

Millot M., S. Tomasi, K. Articus, I. Rouaud, A. Bernard and J. Boustie. 2007. Metabolites from the lichen Ochrolechia parella growing under two different heliotropic conditions. J. Nat. Prod. 70: 316-318.

Molnár K. and E. Farkas. 2010. Current results on biological activities of lichen secondary metabolites: a review. Z. Naturforsch. C. 65: 157-173.

Morita H., T. Tsuchiya, K. Kishibe, S. Noya, M. Shiro and Y. Hirasawa. 2009. Antimitotic activity of lobaric acid and a new benzofuran, sakisacaulon A from Stereocaulon sasakii. Bioorg. Med. Chem. 19: 3679-3681.

Oksanen I. 2006. Ecological and biotechnological aspects of lichens. J. Microbiol. Biotechnol. 73: 723-734.

Paudel B., H.D. Bhattarai, H.K. Lee, H. Oh, H.W. Shin and J.H. Yim. 2010. Antibacterial activities of Ramalin, usnic acid and its three derivatives isolated from the Antarctic lichen Ramalina terebrata. Z. Naturforsch. C. 65: 34-38.

Paudel B., H.D. Bhattarai, J.S. Lee, S.G. Hong, H.W. Shin and J.H. Yim. 2008. Antibacterial potential of Antarctic lichens against human pathogenic Gram-positive bacteria. Phytother. Res. 22: 1269-1271. Pietta P.G. 2000. Flavonoids as antioxidants. J. Nat. Prod. 63: 1035-1042.

Ranković B., D. Ranković and D. Marić. 2010. Antioxidant and antimicrobial activity of some lichen species. Microbiology. 79: 812-818.

Rice-Evans C.A., N.J. Miller, P.G. Bolwell, P.M. Bramley and J.B. Pridham. 1995. The relative activities of plant-derived polyphenolic flavonoids. Free Radic. Res. 22: 375-383.

Slinkard K. and V.L. Singleton. 1977. Total phenol analysis : automation and comparison with manual methods. Am. J. Enol. Vitic. 28: 49-55.

Stocker-Wörgötter E. 2008. Metabolic diversity of lichen-forming ascomycetous fungi : culturing, polyketide and shikimate metabolite production, and PKS gene. Nat. Prod. Rep. 25: 188-200.

Sultana N. and A.J. Afolayan. 2011. A new depsidone and antibacterial activities of compounds from Usnea undulata Stirton. J. Asian Nat. Prod. Res. 13: 1158-1164.

Swenson J.M., C. Thornsberry and V.A. Silcox. 1982. Rapidly growing mycobacteria: testing of susceptibility to 34 antimicrobial agents by microdilution. Antimicrob. Agents Chemother. 22: 186-192. Zhishen J.T. and W.J. Mengcheng. 1999. The determination of flavonoid contents in mulberry and their scavenging effects on super oxide radicals. Food Chem. 64: 555-559. 